\title{
Experimental Analysis of Movements by Prairie Rattlesnakes, Crotalus viridis, During Hibernation
}

\author{
Owen J. Sexton ${ }^{1}$ and Ken R. Marion ${ }^{2}$ \\ ${ }^{1}$ Department of Biology, Washington University, St. Louis, MO 63130, USA and University of Michigan Biological Station, \\ Pellston, MI 49769, USA \\ ${ }^{2}$ Department of Biology, University of Alabama at Birmingham, Birmingham, AL 32594, USA
}

\begin{abstract}
Summary. Prairie rattlesnakes from Colorado, USA, were subjected to two thermal treatments during hibernation. The control treatment was carried out in a surrogate den in St. Louis, MO, USA and followed the normal seasonal thermal regime. Experimental manipulations were carried out in a second den in St. Louis. These series of manipulations reversed or modified the thermal gradient normally expected in wild dens. Periodic observations of the snakes within the control and experimental dens provided corroborative data to support the hypothesis that entry to and exit from dens is regulated by a reversing thermal gradient within wild dens.
\end{abstract}

\section{Introduction}

Two laboratories (Aleksiuk 1970 and Viitanen 1967) have suggested that entry into and exit from hibernacula by snakes in northern areas might be in response to the snakes actively selecting the warmer portions of a reversing thermal gradient within the den. Early in the hibernation or brumation period the surface areas of dens would be warmer than the deeper portions. As both sections cooled, the thermal polarity would be reversed because the surface would loose heat at a faster rate than the deeper part and eventually become cooler. Snakes, in selecting the warmest portion of the surface-underground thermal gradient, would move to the rear or bottom of the den by late fall or early winter. As spring approached, the temperatures along the entire gradient would be increased, but the surface end would gain heat faster and eventually become warmer than the underground end. Snakes would follow this again reversed polarity and exit from the den. Sexton et al. (1980) confirmed the movement of two species (Elaphe obsoleta and Coluber constrictor) along a reversing thermal gradient in a descriptive study carried out in a hibernaculum in western Missouri, U.S.A.

This paper reports the results of an experimental investigation in which the intra-den movements of prairie rattlesnakes, Crotalus viridis, were studied within artificial control and experimental dens. The thermal regime within the control den followed the normal seasonal pattern predicted by the general theory outlined above and substantiated by Sexton et al. (1980). The thermal regime within the experimental den initially followed the natural pattern but was later manipulated by utilizing external heating sources to reverse the thermal gradient in non-seasonal patterns. The predictions were that the snakes should be located along the warmest sections of both control and experimental dens.

\section{Methods}

Twelve Crotalus viridis were collected 12-15 October, 1979, as they moved into a denning area in the short-grass prairie area of eastern Colorado, U.S.A. The principal den was a collapsed cavern in an abandoned coal mine. The snakes were returned to St. Louis and kept in a laboratory until 22 October when the experiment began. A thirteenth animal from New Mexico was added later.

The two artificial dens are underground bunkers formerly used for the storage of ammunition and are located on the Tyson Research Campus, an $800 \mathrm{~h}$ wildlife area operated by Washington University in St. Louis Co., Mo., U.S.A. The walls of the bunkers are of reinforced concrete. The top, rear and sides are covered with earth in which herbaceous and low, woody vegetation are growing. The front wall is exposed. The interior dimensions of the bunkers are: sides $=275 \mathrm{~cm}$, back and front $=273 \mathrm{~cm}$, height $=245 \mathrm{~cm}$. A steel door is located in the front wall. The floor was marked out in a $5 \times 5$ grid system (Fig. 1). Each quadrat measured $55 \times 55 \mathrm{~cm}$ and was given a specific number. Maximum-minimum thermometers were placed at selected quadrats (Fig. 1). The experimental den was chosen by a flip of a coin and was then provided with electric lines to supply various heating elements. Both dens were kept padlocked at all times except when we entered them.

Normal control series. Six snakes were introduced into the control den on 22 October, 1979. Thereafter, 36 visits were made to the den to ascertain the location of the animals relative to the numbered quadrats and to record the current temperature as well as the maximum and minimum temperatures recorded since the last time. At the conclusion of each visit, all snakes were moved to quadrat 8 so that subsequent observations were not dependent upon prior location. The series terminated on 23 April, 1980. All snakes survived.

Experimental series. There were three subsets of this series. Six rattlesnakes were introduced into the experimental den on 22 October, 1979. This den was treated similarly to the control until 26 December, 1979 , to insure that the normal seasonal thermal regime was shared by both. Subseries A began on 26 December, 1979 and continued until 16 February, 1980. During this interval, various heating devices were introduced at locations along the thermal gradient to effect localized changes in both the experimental and control dens. Those in the latter den were not activated. The devices were:

1. Fiber board panels $(120 \times 120 \mathrm{~cm})$ covered on one surface by aluminum foil (Reynolds Wrap-Heavy Duty ${ }^{\circledR}$ ). A $9 \mathrm{~m}$ long heating cable (General Electric Vulkene ${ }^{\circledR} /$ Lead Armoured Heavy Cable) was located between the fiber board and the foil. A thermostat (General Electric heavy duty) was used to regulate the temperature of the coil. These panels were located at positions a, b and e (Fig. 2).

2. A gooseneck lamp with a 100 watt incandescent bulb was located at position d and i (Fig. 2). The bulb was $20 \mathrm{~cm}$ above the floor.

3. Large sand-filled heating panels $2.4 \mathrm{~m}$ long, $1.2 \mathrm{~cm}$ high and $10 \mathrm{~cm}$ thick were covered with galvinized sheet metal on one surface and by $1 \mathrm{~cm}$ thick plywood on the opposite. The $10 \mathrm{~cm}$ wide interior 


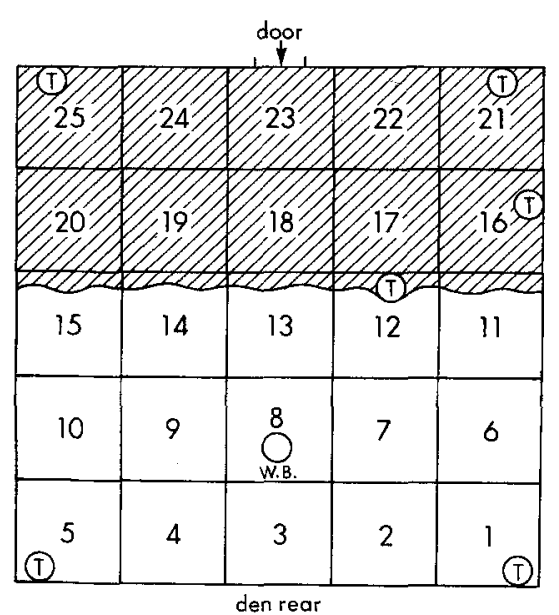

Fig. 1. The grid system of both the control and experiment dens. The cross-hatched area represents the sand added to the den for the heating experiments. W.B. $=$ water bowl and $\mathrm{T}=\operatorname{maximum-minimum}$ thermometer

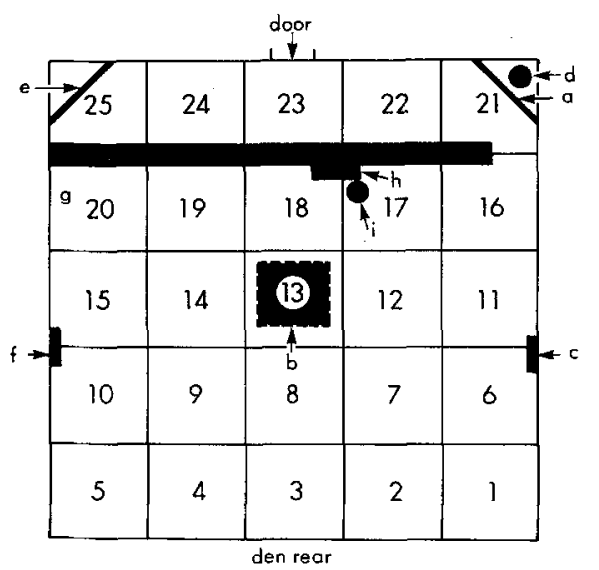

Fig. 2. The location of the various heating devices used to locally modify the thermal gradient in the experimental den. Letters refer to devices discussed in the text

space between the two external panels was filled with sand in which was buried a $18 \mathrm{~m}$ long heating cable with thermostatic control. These units were placed at location $\mathrm{g}$ (Fig. 2).

4. Black vinyl-covered heating panels $(10 \times 27 \mathrm{~cm})$ were attached to plywood boards $(30 \times 30 \mathrm{~cm})$. The panels were at locations $c$ and f (Fig. 2).

These devices provided more-or-less localized or circumscribed thermal hot spots along the normal thermal gradient. They did not necessarily reverse the gradient over any extensive distance. All snakes survived.

Subseries B began on 18 February, 1980, and continued until 23 April. The snakes used in A were again utilized, and all survived. The purpose of this series was to establish a well-defined, reversed thermal gradient to contrast to the control gradient. This reversal was produced by piling sand over quadrats 16-25 (Fig. 1). The sand was warmed by a $18 \mathrm{~m}$ long heating cable (General Electric Vulkene ${ }^{\circledR}$ ) Lead Armoured Heavy Cable) buried at quadrats 21 and 22. The unheated sand at quadrats 24 and 25 served as a control.

Subseries C was initiated on 3 November, 1980, in the experimental den. This experiment was a repeat of $B$ except that the thermal field was expanded to include a second heating cable buried in the sand at quadrats 16 and 17 (Fig. 1). Eleven snakes from 1979-80 were used. A twelfth, from New Mexico, was added. During the course of this experiment one Colorado snake and the New Mexico snake died. The experiment was ended 21 December, 1980. The temperatures
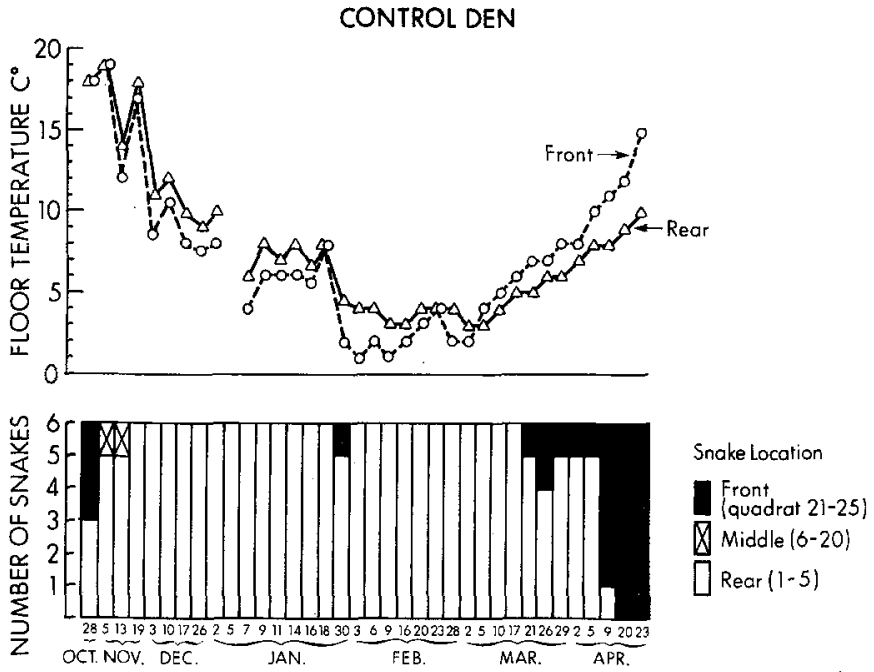

Fig. 3. The location of the six rattlesnakes in the control den relative to the thermal gradient during the winter of $1979-80$

on the unheated side of this experimental chamber (quadrats 5 and 25) served as thermal controls.

The general procedures followed for the experimental series duplicated that observed in the control den. In addition, surface temperatures of all dens and heating devices were measured by using thermistor probes with a Yellow Springs Instrument Co. telethermometer and with a infra-red thermometer. Water was always provided in a bowl located at quadrat 8 in control and experimental dens.

\section{Results}

\section{The Control Den}

The data are summarized in Fig. 3. Initially, the current temperatures at the front and rear of the den were identical, and the snakes were evenly divided between the front and back. By 13 November, the temperatures at the front had dropped below that of the rear and remained so, except for two instances when the temperatures were isothermal, until early March, 1980. During that interval the snakes were located at the rear with a single exception. After the second reversal in thermal polarity occurred in early March, the rattlesnakes were increasingly likely to be found at the front of the den as both temperatures increased.

\section{The Experimental Den}

Subseries A. This den followed the normal, seasonal thermal pattern from 28 October until 26 December, 1979. On the latter date the unactivated fiber board panel was placed vertically across the front cover at quadrat 21 (location a, Fig. 2) with the aluminium foil facing the den interior. When the den was examined on 2 and 5 January, 1980, the snakes were located at the rear. These results indicate that the panel board, per se, was not influencing the distribution of the snakes.

The power was activated on 5 January. On 7 January, the vertical surface of the fiber board was $13^{\circ} \mathrm{C}$, the floor beneath it ranged from $5-7^{\circ} \mathrm{C}$ and the floor temperature at the rear was $7^{\circ}$. All snakes were at the rear. The trial was continued until 9 January with similar results.

The panel was then placed horizontally in the center of the den (location b, Fig. 2) with the foil side uppermost. On 11 January, all snakes were still at the rear. The temperature of the 
front floor was $5.5^{\circ} \mathrm{C}$, that of the panel surface was $7^{\circ}$ and that of the den rear was $6.5^{\circ} \mathrm{C}$. Apparently, heavy amounts of rain and/or snow caused a short circuit in the electric lines supplying the den so that an insufficient amount of current was available to raise the panel temperature much above ambient. Similar results were observed on 14 January. The short circuit was repaired.

On 14 January, two other heating devices were utilized. The black vinyl heating panel was placed horizontally along one wall (location c, Fig. 2), and the gooseneck lamp was placed in a forward corner (location d, Fig. 2). Both were activated. The fiber board panel was disconnected and moved to a vertical position in the second, forward corner (location e, Fig. 2). 'Two days later all six rattlesnakes were still at the den rear. Relevant temperatures were: unheated front and rear floors $=8^{\circ}$ and $9^{\circ}$, respectively; heated vinyl panel $=28^{\circ}$; lighted floor at quadrat $21=11^{\circ}$; unheated fiber board panel $=8.5^{\circ} \mathrm{C}$.

The next treatment, begun on 16 January, added an unheated vinyl panel along the wall (location f, Fig. 2). The snakes were released on the warm floor beneath the gooseneck lamp at quadrat 21 to see if they would remain in a warm area. The next check on 18 January showed that all six snakes were at the rear. Surface temperatures were: unheated front and rear floors and vinyl panel, isothermal at $7^{\circ} \mathrm{C}$; quadrat 21 heated by lamp, $11^{\circ} \mathrm{C}$; heated vinyl panel $=32^{\circ}$.

On 27 January the large, sand-filled panel was set in place (location g, Fig. 2); its metal surface faced the rear of the den. At the 30 January visit, all snakes were in the den rear. The front floor temperature was $1-3^{\circ} \mathrm{C}$, the metal surface of the panel at the point $10 \mathrm{~cm}$ above the floor was $14^{\circ} \mathrm{C}$ while the floor immediately below was $5^{\circ} \mathrm{C}$. The rear floor was also $5^{\circ} \mathrm{C}$. The snakes were not displaced.

On 3 February the rattlesnakes were still at the den rear. The heated panel was $15^{\circ} \mathrm{C}$ and the floor below it was $5^{\circ}$. The rear floor was also $5^{\circ}$, but the front varied from $0^{\circ}$ to $2^{\circ} \mathrm{C}$. An activated black vinyl panel (location h, Fig. 2) was placed adjacent to the sand-filled one for the next experiment.

At the 5 February trip, all six snakes were again at the rear where the floor temperature was $5^{\circ} \mathrm{C}$. The front floor was $2-$ $3^{\circ} \mathrm{C}$. The sand-filled panel had a temperature of $15^{\circ} \mathrm{C}$, and the unheated floor adjacent to it was $5^{\circ} \mathrm{C}$. The vinyl panel was at $18^{\circ} \mathrm{C}$. A lighted gooseneck lamp was positioned over the black vinyl panel (locations $h$ and i, Fig. 2) for the subsequent test.

All snakes were at the back of the den on 9 February. There was a clear difference in the temperature of the den floor at the and back, front $5^{\circ} \mathrm{C}$ vs. $2^{\circ} \mathrm{C}$, respectively. The sand-filled panel surface was $15^{\circ} \mathrm{C}$ and the floor beneath it was $6^{\circ} \mathrm{C}$. The lighted vinyl panel registered $36^{\circ} \mathrm{C}$.

All of the heating devices remained in place for the final experiment. The snakes were released at the heated and lighted vinyl panel (locations $h$ and i, Fig. 2) on 9 February. When next visited on 16 February, three of the snakes were at the den rear, one was in the core of a building block used to support the sand-filled panel at quadrat 25 (Fig. 2) and two were in a similar building block at quadrat 20 . The unheated front and rear floor temperatures were $1-4^{\circ} \mathrm{C}$ and $5^{\circ} \mathrm{C}$, respectively. The metal surface of the sand-filled panel was $14.5^{\circ} \mathrm{C}$ and the floor beneath was $5.5^{\circ} \mathrm{C}$. The lighted and heated black vinyl panel was $35^{\circ} \mathrm{C}$.

Subseries B. This experimental sequence, utilizing a heated bed of sand (Fig. 1), began on 18 February, 1980.

On 20 February, all six rattlers still remained at the rear where the floor temperature was $5^{\circ} \mathrm{C}$. The heated sand (quad-

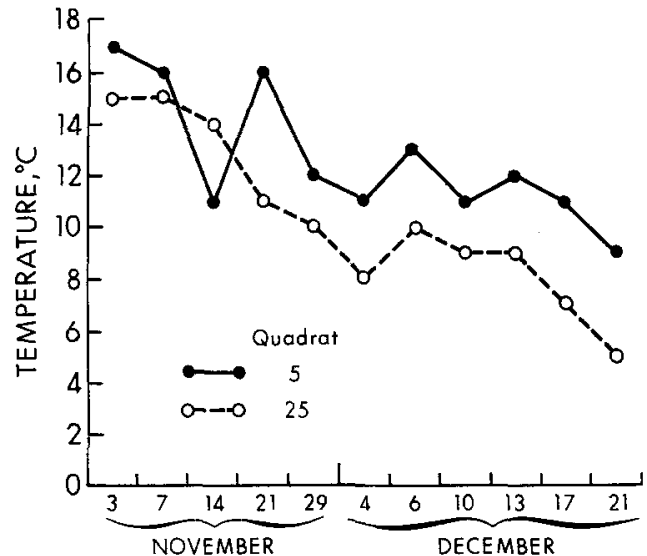

Fig. 4. The thermal regime of the unheated (control) side of the experimental den during the fall and winter of 1980

rat 21) was $13^{\circ} \mathrm{C}$ and the unheated sand was $3^{\circ} \mathrm{C}$. However, tracks on the heated portion indicated that some snakes had visited that area. No tracks were observed on the unheated portion. The sand was smoothed to remove tracks made earlier.

Three days later all of the snakes were at the rear but the heated sand was covered with tracks while the unheated sand was still smooth. The heated sand was $12^{\circ} \mathrm{C}$, the unheated $4^{\circ} \mathrm{C}$. The rear varied from 5 to $7^{\circ} \mathrm{C}$. The pattern remained the same for 28 February. This time the gooseneck lamp was placed at quadrat 21 and the snakes were released beneath it.

Four of the rattlers were at the rear on 2 March, and both sides of sand bed were covered with tracks. The gooseneck lamp was removed, and the snakes were released at quadrat 21 . On 5 March, five snakes were on quadrat 16 (the margin of the heated sand bed).

The next six observation periods, 10 March through 2 April, the heated sand showed the tracks of many more snakes than did the unheated side on the five of six occasions. On the sixth the tracks were equally frequent.

Four snakes were at the front on 5 April, one at quadrat 25 , the others on the heated sand. All were at the front on 20 April. At this time the electric power was turned off. On the final day, most snakes were again at the front.

Subseries C. The final set of experiments was initiated on 3 November, 1981 and continued until 21 December, 1981. The temperature of the unheated side of the experimental chamber (quadrats 5 and 25) reflected the normal, seasonal pattern (Fig. 4). The thermal regime of the heated side represented a reversal of the seasonal pattern (Fig. 5). Initially, the thermostatic control of the heating cables buried in the sand was set at $32^{\circ} \mathrm{C}$ from 3 to 29 November. The result was that a steep thermal cline was established between the front and rear of the den (see quadrats 21, 16 and 1 in Fig. 5). Most of the animals were located at the four heated quadrats out of the 25 quadrats available during four visits. Beginning 29 November and continuing over the next three trips, the thermostat was successively decreased by $5.5^{\circ} \mathrm{C}$ increments to a low of $10^{\circ} \mathrm{C}$ on 10 December. On the first of the three subsequent visits to the den, the temperature of the front was still above that at the rear, although progressively less so. Even so, at least half of the rattlesnakes were located on the four heated quadrats. On the 13 December visit, the temperature at the rear exceeded that at the front for the first time, and the overwhelming majority of the snakes were located at the rear. The heating was discontinued on that date so that the normal, thermal polarity was re-established. 


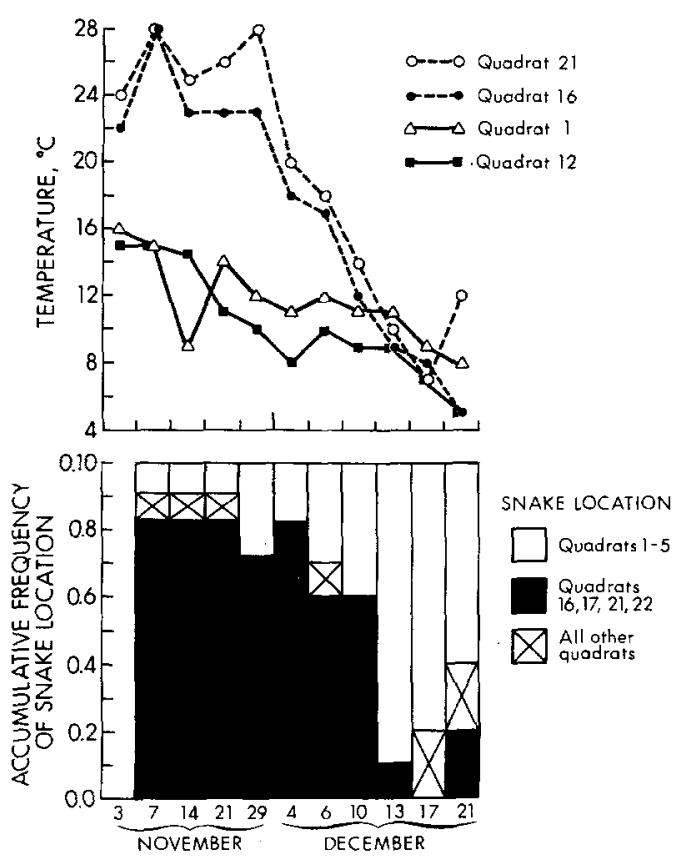

Fig. 5. The distribution of the snakes relative to the experimentally reversed thermal gradient in the fall and winter of 1980

On 17 December, no snakes were recorded at the den front, two were halfway back, and eight were at the rear.

The final experiment was to place the lighted gooseneck lamp in one of the front corners (location d, Fig. 2) on 17 December. When the den was visited for the final time on 21 December, two snakes were in quadrat 21 , two were halfway back (quadrats 11 and 15) and the remainder were at the rear of the den.

\section{Movements Within the Den}

In order to emphasize that hibernating snakes are capable of exploiting a reversible thermal gradient, it is essential to establish that they are not passively torpid but are fully capable of travelling throughout the den.

The first evidence was obtained accidentally. On 9 January, 1980 , all six snakes in the control den were in quadrat 1 . The current floor temperatures at the den rear and front were $7^{\circ}$ and $6^{\circ} \mathrm{C}$, respectively. The six snakes of the experimental den were located in three of the rear quadrats. The rear and front floor temperatures were $8^{\circ}$ and $6^{\circ} \mathrm{C}$, respectively. After the two sets of snakes were displaced to their usual release site, we left the dens. Returning after $25 \mathrm{~min}$ we found that the snakes were distributed throughout all sections of both dens, many of them being located at the front.

A systematic study was made on 23-24 February. At 1000 , 23 February all snakes were located at the rear of the two dens. Floor temperatures at both front and rear of the control den were $4^{\circ} \mathrm{C}$; those of the experimental den were $5-7^{\circ} \mathrm{C}$ at the rear and $4-12^{\circ} \mathrm{C}$ at the front. The snakes were then moved to the release point near the den center. Within $1 \mathrm{~h} 3$ control snakes were at the back of the den, one was at the front and two were in the middle section (quadrats 13 and 20). Over the next $1.5 \mathrm{~h}$, two more snakes returned to the rear position. After another $3 \mathrm{~h}$, or $5.5 \mathrm{~h}$ after release, all snakes were located against the rear wall. They were all in the same location the next day at 1030 . The experimental snakes exhibited the same type of behavior.

\section{Discussion}

Overall, both the thermal regime and the distribution of the snakes within the 1979-80 control dens follow the seasonal pattern predicted by the general hypothesis (Fig. 3). The experiment evidently was initiated at a time when the temperatures of the front and rear floor were nearly isothermal. At that time half of the snakes were located at the front and half at the back. As soon as the thermal polarity was established, the snakes moved back toward the rear. The second reversal of the thermal polarity recurred between 2 and 5 March. At this time the den temperatures were still very low and snakes did not start to move forward until mid-March when den temperatures reached $5^{\circ} \mathrm{C}$ or above. By the time the forward temperature near or above $10^{\circ} \mathrm{C}$, the snakes were located at the front of the den. In nature, the snakes would presumably have been ready to leave the den as early as 9 April.

The strongest experimental evidence supporting the basic hypothesis is from subseries $\mathrm{B}$ and $\mathrm{C}$. The physical difference between these two series was that the number of heating coils and their spacing were so arranged in $C$ that a steeper thermal gradient was established.

Series B began on 18 February, 1980. There was a lag in the movement of the snakes to the front of the den. Part of this lag is due to the time necessary to reverse the normal, thermal gradient established during the winter. The first snakes were observed at the front of the den on $2 \mathrm{March}$, at least 19 days before they occurred there in the control den. Low numbers were located forward until 5 April. At the same time, tracks were much more evident on the heated sand than on the unheated substrate. This indirect evidence of snake location indicates that their movement was directional. The 1979-80 control data indicate that the forward movement of snakes in that den was completed by 9 April. Between 2 March and 9 April, a total of six snake-observations were made of rattlers at the front of the control dens, but 21 observations were made for the experimental den $\left(\chi_{c}^{2}=18\right.$ with 1 D.F., $\left.p \geqslant 0.005\right)$.

Subseries $C$ differed from $B$ in that the thermal gradient was not reversed but the early fall one was maintained (Fig. 5). The temperature regime of the unheated side (quadrats 5 and 25, Fig. 4) clearly indicate that the snakes would be expected to follow the distribution shown in the 1979-80 control den were the other side (quadrats 1, 16 and 21, Fig. 5) not heated. The actual distribution of snakes at the front on the heated sand demonstrates that they responded strongly to a definite thermal gradient. This differential was maintained until that time when the temperature of the heated sand was decreased below that of the rear floor. At that point the snakes shifted to assume their normal winter location at the den rear.

The data from experimental subseries A did not directly support the basic hypothesis. Few snakes were associated with the series of heating devices provided, but, instead, they responded to the seasonal regime. The difference in heating patterns of $A$ versus $B$ and $C$ seems to account for discrepancies in the distribution of the snakes. Most of the heating devices in A were circumscribed in area and local in effect. For example, the black vinyl panel measured $27 \times 10 \mathrm{~cm}$. Such a device would not reverse the entire gradient, but be a localized step perturbation along it. Even the effect of the lighted gooseneck lamp seems to have operated in this fashion. Thus, the results of A suggest that the snakes are responding to a gradient as a unit, not to localized "hot spots".

The movements of the snakes throughout the den after they are removed to the release point suggests that they do not imme- 
diately return to the preferred site but that they wander. Perhaps these movements are exploratory in nature and the snakes are assessing the thermal field before settling down. Oddly, neither vision nor the pit organ seems to play an important role in this assessment. Snakes rarely utilized the area beneath the lighted lamp nor did they respond to the large, vertical, heated surface of the sand-filled panel. Perhaps assessment of the thermal properties of the den is made by thermal receptors in the body which detect temperature differences as the animals crawl about.

The utilization of the reversing polarity of a thermal cline by hibernating snakes would appear to have a strong selective advantage to a northern ectotherm. The reversals are the result of differential cooling or heating of the soil substrate. As such, localized weather effects, such as occasional warm days in midwinter, would not be frequent enough to reverse the gradient. This lag would be insurance that snakes would not emerge from hibernation until thermal conditions were beneficial and predictable. A second benefit is that, by following the warmer end of the gradient, the snakes are removed from the deleterious effects of sudden drops in temperature outside of the den which could drop temperatures near the den entrance to below minimum lethal limits of the snakes.

Acknowledgements. The University of Alabama at Birmingham and Washington University provide financial support. Dr. Richard Coles offered many constructive ideas about experimental design. Mr. Jack Diani was responsible for the excellent health of the snakes.

\section{References}

Aleksiuk M (1970) The effects of in vivo light and temperature acclimation on in vitro responses of heart rate to temperature in a coldclimate reptile, Thamnophis sirtalis parietalis. Canadian Journal of Zoology 48:1155-1161

Sexton OJ, Hunt SR (1980) Temperature relationships and movements of snakes (Elaphe obsoleta, Coluber constrictor) in a cave hibernaculum. Herpetologica 36:20-26

Viitanen P (1967) Hibernation and seasonal movements of the viper, Viper berus berus (L.) in southern Finland. Ann Zool Fennici $4: 472-546$

Received February 23, 1981 